\title{
Los anclajes en la proximidad y la movilidad cotidiana. Retrato de tres barrios de la ciudad de Santiago de Chile
}

Alejandra Lazo. Universidad de Los Lagos, Osorno, Chile.

Rodrigo Calderón. Universidad Alberto Hurtado, Santiago, Chile.

RESUMEN | Situándonos en el actual escenario de lo que se ha denominado una "movilidad generalizada” de la sociedad,, en este artículo se aborda la importancia del territorio de proximidad -casa y barrio- como un soporte que permite generar los anclajes necesarios para hacer frente a las tensiones espacio-temporales asociadas a la movilidad. A partir de un enfoque de tipo cualitativo se realizó una investigación en tres barrios de la ciudad de Santiago de Chile que permitió plantear que a pesar del aumento de la movilidad, existe todavía entre los habitantes una identificación y valorización de los lazos simbólicos y afectivos, así como de las prácticas que tienen lugar en la casa, el barrio y la vecindad. De este modo, se concluye para el caso de la ciudad de Santiago de Chile, la importancia de leer la movilidad a partir de los anclajes tejidos en la proximidad.

PALABRAS CLAVE $\mid$ movilidad, geografía urbana, integración social.

ABSTRACT | In the context of the current scenario of what has been referred to as the "generalized mobility" of society, this article addresses the importance of proximate territory -home and neighborhood- as the foundations for dealing with the strategic tensions brought about by social mobility. Based on a qualitative research approach, carried out in three areas of the city of Santiago de Chile, the article concludes that despite the increase in mobility, the inhabitants of the city identify with and preserve the symbolic and affective ties and practices that take place at home, and the areas around the block and the neighborhood scales. In this way, in the case of the city of Santiago de Chile, the importance of construing daily mobility based on such attachments that are weaved into territorial proximity becomes increasingly clear.

KEY WORDS | mobility, urban geography, social integration.

Recibido el 10 de diciembre de 2012, aprobado el 21 de agosto de 2013

E-mail: Alejandra Lazo, alejandra.lazo@ulagos.cl | Rodrigo Calderón, rodrigo4cs@gmail.com 


\section{Introducción}

En el escenario de lo que se ha denominado una "movilidad generalizada" de la sociedad (Bourdin, 2005; Lannoy \& Ramadier, 2007), y del mandato social que nos obliga a esa movilidad (Le Breton, 2004; Martucelli, 2006), se instala la pertinencia de la pregunta sobre los modos de vida que se están desarrollando en la ciudad. Este aumento de la movilidad significa una transformación en la relación del individuo con el espacio urbano. En este sentido, los adelantos tecnológicos en los medios de transporte y telecomunicaciones han trastocado las morfologías tradicionales del habitar, donde los límites de los barrios ya no son más los límites funcionales trazados por las prácticas sociales (Pattaroni, Kaufmann, Pedrazzini, Bolay \& Rabinovich, 2008).

A partir de esta movilidad generalizada, varios autores seńalan la emergencia de un nuevo paradigma dentro de las ciencias sociales, el de las "nuevas movilidades” (Sheller \& Urry, 2006; Hannam, Sheller \& Urry, 2006; Cresswell, 2010). Sin embargo, este nuevo paradigma no significa que las nociones relacionadas con la inmovilidad, como fronteras y límites, lugar, territorio y paisaje, dejen de tener importancia y pierdan capacidad explicativa (Cresswell, 2010). Más bien, se trata de comprender la movilidad a luz de las relaciones constitutivas del movimiento, las inmovilidades relativas y las diferencias en la velocidad (Adey, 2006). En palabras de Hannam, Sheller y Urry (2006), no hay un aumento lineal en la fluidez sin amplios sistemas de inmovilidades. La vida social y las complejidades de la vida parecen requerir de anclajes que sean sólidos, estáticos e inmóviles.

En consonancia con lo anterior, se plantea la existencia de un territorio de proximidad, el que no solo debe ser pensado a partir de límites físicos, como el entorno más cercano al individuo -la casa, el barrio y las relaciones de vecindad-, sino también como un espacio que permite construir un anclaje para que los habitantes puedan moverse cotidianamente. De este modo, planteamos la hipótesis del territorio de proximidad como un soporte que ofrece los anclajes necesarios para las prácticas de movilidad cotidiana de los habitantes de la ciudad de Santiago de Chile. Este territorio es movilizado por los habitantes como una manera de sobrellevar las tensiones espacio-temporales asociadas a la movilidad generalizada de la sociedad.

En efecto, la proximidad puede ser conceptualizada ya sea como un espacio delimitado material o simbólicamente, o bien como una red o rizoma donde se definen varias lógicas y actividades humanas en el espacio y el tiempo. El territorio de proximidad no puede ser comprendido como un simple y pasivo "receptáculo" de las actividades que se realizan en él, sino como ofreciendo los apoyos o anclajes necesarios para la realización de la cotidianidad, y de hecho "moviéndose y siguiendo" a las personas (Pattaroni et al., 2008; Jirón \& Iturra, 2011).

Para dar fundamento a lo anterior, hemos divido este artículo en tres secciones. En la primera se exploran los planteamientos teórico-metodológicos que guían el debate en torno a la movilidad, los anclajes y la proximidad. En la segunda sección, se presentan los casos de estudio y la metodología utilizada, para luego dar cuenta de los resultados del trabajo etnográfico realizado en tres barrios de la ciudad de Santiago de Chile, mostrando cómo el territorio de proximidad participa en las 
prácticas de movilidad cotidiana de los habitantes. Finalmente, en la última sección concluimos con las reflexiones finales que surgen de esta investigación.

\section{La movilidad, los anclajes y la proximidad}

Como explica J. Urry (2003), la vida móvil está constituida por mundos materiales que implican nuevos y distintos anclajes que permiten, producen y presuponen nuevas movilidades extensas. Si bien Urry no se refiere específicamente a los anclajes generados en los territorios de proximidad, sino más bien a las infraestructuras que permiten la movilidad, se deja entrever cómo los anclajes también tienen una profunda implicación en la vida social, la que se estabiliza por medio de ellos. Como resultado, la movilidad y los anclajes constituyen y están constituidos por relaciones sociales (Adey, 2006).

\section{El territorio de proximidad y los anclajes}

El concepto de territorio que utilizamos en esta investigación intenta completar la noción clásica que lo entiende como una simple superficie, como aquel espacio concreto, aquella área materializada por el ejercicio de la acción humana repetitiva (Monnet, 2010). Así, retomando la propuesta de este autor, por un lado se lo debe pensar como un sistema que integra los valores que estructuran las representaciones y los significados de dicho espacio material, esto es, la territorialidad. Y por el otro, se lo debe concebir desde la perspectiva de las acciones que se producen sobre él y que lo definen en tanto territorio, vale decir, lo que se conoce como la territorialización (Di Méo, 1999; Monnet, 2010). Por lo tanto, se propone una coexistencia de territorios en el espacio urbano, entre los cuales se encuentra el territorio de proximidad.

Del mismo modo, entenderemos la movilidad cotidiana más allá del simple desplazamiento desde un punto A hasta un punto B, para concebirla como aquella dimensión que permite desarrollar modos de vida íntegros, con inscripciones espaciales diversas y proyectos de vida, por medio de la construcción de lugares en los que se pueda permanecer, pero también desde los cuales se pueda salir a practicar la ciudad (Kaufmann, 2011).

Entendido esto, se propone comprender el territorio de proximidad como un soporte que ofrece los anclajes necesarios para las prácticas de movilidad cotidiana (Lazo, 2012). De este modo, no se trata solo de un espacio por donde transitan los habitantes, sino que, además, es un territorio que propone orientaciones específicas para las actividades (May Du, 2009). En este sentido y retomando las ideas de I. Joseph (1998) sobre la ciudad, es posible plantear que el territorio de proximidad es un recurso y, al mismo tiempo, un lugar de proposición para la acción, que implica competencias de usos y/o barreras, según sea la situación. El territorio de proximidad como soporte que sirve o restringe la movilidad cotidiana podría fomentar prácticas intensas en la urbe, también una movilidad a escala local, o bien la combinación de estas dos prácticas. Las connotaciones que tenga la proximidad (positiva, negativa), las relaciones tejidas en este territorio (sociales, afectivas, 
identitarias, históricas), la infraestructura construida, influirán y estructurarán las prácticas de movilidad de los individuos ${ }^{1}$.

\section{Los anclajes en la casa y el barrio}

Antes de entrar en los análisis de terreno y para demostrar brevemente la importancia de la proximidad para las prácticas cotidianas de movilidad, queremos detenernos en dos territorios centrales para los habitantes: la casa y el barrio.

El primero de ellos aparece como el territorio por excelencia donde los habitantes encuentran refugio. En este sentido, sin importar su tipo, material y localización, la casa se transforma en el deseo de todos los grupos sociales. Desde esta perspectiva, el ser propietario constituye un logro y una ascensión social, además de una inversión y un patrimonio familiar (Bonvalet $\&$ Dureau, 2000). Es por esto que la casa se constituye en un lugar cargado de sentidos y significados.

Desde la casa se construyen los lazos y relaciones con los territorios que nos rodean. Es desde ella que las exploraciones exteriores se realizan; desde ella se planean las movilidades, las incursiones, las formas de relacionarse con lo que está más allá. Al mismo tiempo, ella es un refugio, el lugar adonde se regresa después de una larga jornada.

La casa es, entonces, el primer anclaje, un lugar de "reposo" y a la vez un generador de movimientos hacia otros territorios, como el barrio y la ciudad. La casa se revela, entonces, como el primer indicador de la relación de los habitantes con sus territorios. La casa como soporte.

Asimismo, y cuando se piensa en la casa, se la debe comprender dentro de una lógica familiar: es el lugar donde las estrategias familiares se ponen en marcha en pos de un proyecto colectivo, el que implica una movilización más allá de esta escala. Desde la casa es que se pueden planear las actividades y estrategias que las personas desarrollan sea como individuos o como familia. El anclaje familiar se produce, primero, por medio de la casa.

La casa, como soporte, se constituye entonces en el nicho por excelencia desde donde los habitantes construyen y articulan sus identidades, movilidades, inmovilidades y percepciones de la ciudad. Se podría plantear la casa como el territorio de mediación entre el adentro y el afuera (el barrio, la calle y la ciudad). Es en ella que se produce una apertura hacia los otros territorios (Lindón, 2005; Ontiveros, 2006).

Habitar una casa lleva consigo la necesidad de desplazamientos que se articularán por medio y con ella. Sea que se viva en la periferia pobre, en el centro de la ciudad o en la periferia más acomodada y bien conectada, todos los individuos y sus familias deberán construir sus territorios a partir de ella. Porque es un lugar de refugio y sentido, por su construcción como centro de consumo y de producción doméstica, y por la satisfacción de los proyectos personales de sus miembros, la casa debe inscribirse en un "sistema de lugares" que la ligan con el resto del mundo, y la movilidad se constituye en el medio para hacerlo (Pinson \& Thomann, 2001).

1 Sin embargo, no se debe olvidar que hay también otras variables, como el nivel socioeconómico, edad, género, etcétera, que influyen en las prácticas de movilidad cotidiana, y que pueden dar más o menos márgenes de libertad a los individuos. 
Sin embargo, si bien la casa significa una apertura hacia lo que está más allá, sus habitantes manifiestan en la actualidad un regreso a su interior y hacen de la casa un lugar no solo de sentidos, sino también de prácticas. Ahora no solo es un lugar familiar y de descanso, sino además de diversión, de trabajo, de encuentro. Asimismo, ella es una "casa móvil" - conectada por medio de las comunicaciones, sobre todo Internet-, de la que no se necesita salir para estar en contacto con los otros territorios. Aparece la casa como un lugar aislado, cerrado y protegido del afuera. Podemos decir que en una sociedad cada vez más individualizada asistimos al repliegue domiciliario. En este sentido, y en un universo donde los desplazamientos se multiplican y se extienden, explica François Ascher (1998), sin dejar lugar a paradas intermediarias, los habitantes toman cada vez más la vivienda como el territorio por excelencia.

Por otro lado, no se debe olvidar que si bien la casa es concebida como el primer refugio, al mismo tiempo que lugar generador de movimientos, ella no es el único anclaje para los habitantes. En efecto, el barrio es una escala intermedia -entre la casa y la ciudad- que se constituye también en un elemento central en la dialéctica entre el territorio de proximidad (casa y barrio) y la movilidad.

Observamos, entonces, que el aumento de la movilidad no reemplaza ni hace desaparecer el territorio de proximidad; lo que hay, más bien, es un nuevo fenómeno: la movilidad viene a complementarse con la proximidad (Rémy, 1996). De hecho, el barrio aparece como un lugar todavía importante para las prácticas de movilidad cotidiana, pues ofrece los anclajes para conectarse con el exterior.

Salcedo y Pérez (2006), al explicar el sentido del barrio en la realidad latinoamericana, plantean que no solo existe barrio donde las interacciones entre vecinos son más estrechas, sino también allí donde el contacto se reduce al mínimo. Lo que hay, señalan, es una reactualización de las prácticas y relaciones barriales, donde "estas pueden aparecer bajo diversas modalidades, reduciéndose a un contacto mínimo, pero en el cual siempre hay un reconocimiento del otro en tanto que ser social" (p. 12).

Desde aquí se plantea comprender el barrio - sea este una villa, un condominio cerrado, una población- como un territorio de identificación social, familiar y cultural importante para los habitantes de la ciudad de Santiago de Chile, el que se convierte en un punto de anclaje central desde donde los individuos ven y viven la ciudad.

Recientes investigaciones llevadas a cabo en contextos latinoamericanos (Lindón, 2006; Márquez, 2006; Duhau \& Giglia, 2008; Jouffe \& Campos, 2009; Lazo, 2012) han demostrado cómo el barrio tiene todavía una influencia importante en las prácticas cotidianas de los habitantes. De este modo, el arraigo -o no arraigoal barrio, es decir, la relación que se teje con este territorio, así como la historia construida, las redes sociales, vecinales y la identidad, tendrán una influencia en los desplazamientos urbanos. Los atributos que tenga el barrio (aspectos morfológicos y funcionales), las significaciones que le dan sus habitantes, el tipo de arraigo y la representación espacial, ejercerán una influencia importante en la movilidad cotidiana de los individuos. Otras variables como la edad, el sexo, el tipo de trabajo, el 
nivel económico serán también elementos que pesan en la comprensión del habitante y su territorio, dando cuenta de un tipo específico de movilidad.

De hecho, el barrio constituye un medio, una entidad productiva que tiene propiedades con efectos sobre el curso de las acciones humanas, sobre las maneras de habitar y de cohabitar (Authier, Bacqué \& Guérin-Pace, 2007). Las significaciones que se tengan del lugar de residencia (casa-barrio), la naturaleza del arraigo a ese territorio, las representaciones espaciales, estarán en directa relación con la movilidad de los individuos. Así, quienes conciben el barrio como un soporte sociorrelacional importante, podrían privilegiar prácticas en este territorio, mientras que quienes sienten el barrio como inseguro, hostil, deteriorado, serían más propensos a tener prácticas de distanciamiento de esta escala o bien un repliegue hacia el domicilio.

Finalmente, la casa y el barrio aparecen como territorios de múltiples dimensiones y significados, que toman relevancia en su relación con el contexto urbano, social y político que los rodea. Su importancia es comprendida solo si se los analiza a la luz de los componentes espaciales que los conforman (por ejemplo: la estructura y materialidad de la casa, calles, espacios verdes) y de los que participan (comuna, ciudad, periferia), así como si se los confronta con las ideas que se tiene de ellos. En este sentido, el territorio de proximidad debe entenderse en relación con los otros territorios que lo conforman y con los que se vincula, y también en relación con la historia e identidad de sus habitantes, con las prácticas y las percepciones, con la forma urbana y las intervenciones públicas.

\section{Proximidad y movilidad cotidiana en tres barrios de Santiago de Chile}

\section{Los terrenos de estudio y la estrategia metodológica}

Se eligió para estudiar la relación entre el territorio de proximidad y la movilidad cotidiana tres barrios emblemáticos de la ciudad de Santiago de Chile, cuyos habitantes se caracterizan por una inscripción territorial bien referenciada en su localidad. Interesaba la escala barrial, porque esta aparecía como la unidad de observación más pertinente para estudiar la complejidad urbana (Grafmeyer, 2006, p. 30).

El primer territorio estudiado fue El Castillo en la comuna de La Pintana, un barrio cuyos habitantes son de escasos recursos, que surgió en los años ochenta fruto de las erradicaciones llevadas a cabo en la época de la dictadura militar. Se localiza bastante lejos del centro de la ciudad, específicamente en los márgenes de la periferia sur.

El segundo terreno estudiado fue la Comunidad Ecológica de Peñalolén, sector de clase acomodada que se formó en los albores de los ańos ochenta, en la periferia oriente de la ciudad, por un grupo de familias descontentas de la vida urbana.

Finalmente, el tercer y último terreno que presentamos es la Unidad Vecinal Portales - más conocida hoy como Villa Portales-, conjunto de casas y edificios construidos por el Estado en los ańos cincuenta, para la clase media trabajadora del país. Este proyecto, emplazado en el pericentro de la ciudad, se constituyó en un proyecto emblemático del ideal modernizador del Estado. 
FIgura 1 | Ubicación de los tres terrenos de estudio en Santiago de Chile

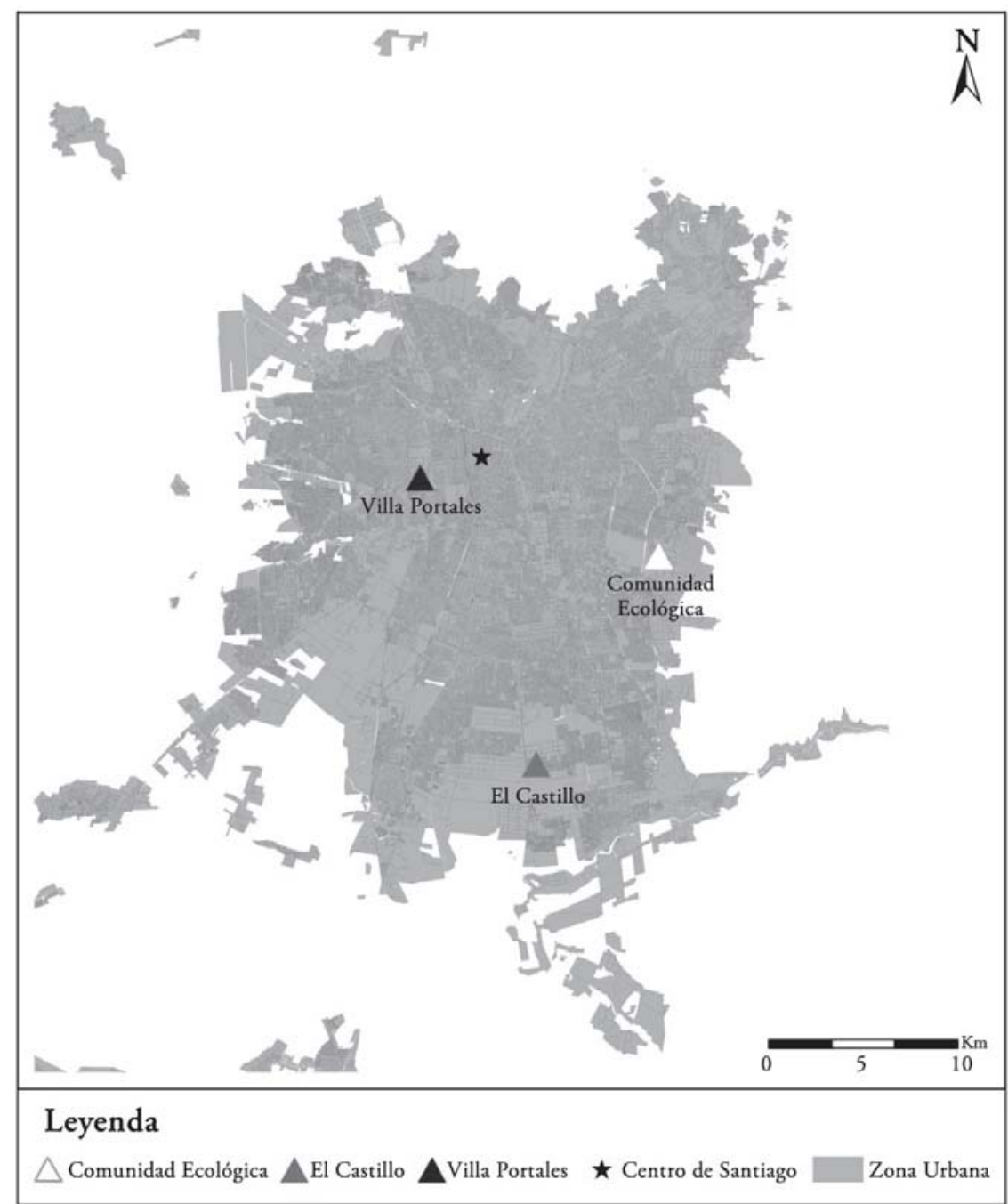

FUENTE ELABORACIÓN PROPIA

Se seleccionaron estos tres barrios no con la intención de compararlos, sino para dar cuenta de una diversidad de comportamientos y experiencias espaciales que corresponden a las distintas formas de habitar la casa, el barrio y la ciudad. A partir de un acercamiento etnográfico, se realizaron observaciones y visitas reiteradas a los terrenos, conversaciones informales y entrevistas (51 entrevistas abiertas) con los habitantes. Las entrevistas estuvieron estructuradas en torno a tres tópicos: casa, barrio y ciudad. El principal objetivo fue conocer y comprender las prácticas cotidianas, los sentidos y los significados otorgados a estos tres territorios. Respecto de la muestra de entrevistados, esta estuvo constituida por personas de diferente sexo y edad -jóvenes, adultos y personas mayores- de los tres sectores estudiados, para así incorporar al estudio las distintas prácticas y formas de relacionarse con el territorio propias de cada lugar y de cada grupo humano. 
En América Latina, a pesar de las investigaciones que se han realizado sobre transporte y políticas de vivienda, la relación de los habitantes con su territorio a partir de la movilidad residencial y cotidiana ha sido muy poco estudiada. En efecto, la comprensión de la instalación de los grupos en su territorio, sus anclajes, movilidades e inmovilidades, permite constatar que los territorios practicados -esto es, vividos y experimentados por un sujeto- son múltiples y variados, espacial y temporalmente, respondiendo a una serie de lógicas y experiencias cotidianas.

\section{Barrio El Castillo}

El primer territorio que presentaremos es el barrio El Castillo, cuyos habitantes provienen de asentamientos precarios e informales -campamentos- originalmente de distintas zonas de Santiago, que con la política de erradicación de los años ochenta fueron expulsados a áreas periféricas de la ciudad, donde se les entregó una vivienda precaria, pero definitiva. Si bien esta política de erradicación puede ser leída como una estrategia política y mercantilista, al fragmentar a grupos poblacionales muchas veces organizados (Rodríguez \& Winchester, 2004) y liberar áreas de alto valor de suelo de los asentamientos irregulares, esta expulsión permitió a las familias erradicadas acceder a algo que no tenían, es decir, a la casa propia.

Estábamos contentos, felices, porque fue un cambio radical, ya definitivo. No me preocupé más de andar p'arriba y p’abajo (Hombre adulto, El Castillo).

Es mi espacio, es mi casa (...) paso la mayor parte del tiempo acá, porque no hay nada como tu casa (...) (Mujer adulta, El Castillo).

Así como la casa aparece para los habitantes de El Castillo como un lugar cargado de sentidos, el barrio es también un universo de significados en donde cada uno se reconoce y reconoce a los otros, y puede distinguir los referentes espaciales, relacionales e históricos que comparte con los otros habitantes del lugar. El barrio no solo es un "espacio físico" que contiene las prácticas, sino también el territorio de las relaciones sociales y de los universos de significación.

Aquí se han criado dos generaciones, digamos. Yo traje a mis hijos de ocho y diez años (...) de ahí crecieron los niños. Muchos se han ambientado aquí, se casaron, otros se fueron, otros están cerca de aquí, de mi casa (Hombre mayor, El Castillo).

De esta forma, el territorio de proximidad (barrio) se presenta como una fuente de recursos afectivos, sociales y económicos importantes para los habitantes, ello se manifiesta en los anclajes y en las movilidades que tienen en el territorio.

Estoy acostumbrado ahora y, por lo demás, a veces salgo, me conoce la mayoría de la gente, los ubico y no tengo ningún temor al salir en la noche; no tengo problema, conozco a los que son malucos (Hombre mayor, El Castillo).

En el estudio se propuso tomar distancia de los planteamientos según los cuales el barrio es un lugar de cohesión y lazo social que está desapareciendo (Ascher, 1998), para comprender cómo es reactualizado a partir de las prácticas de sus habitantes. El barrio sigue siendo hoy un territorio soporte para las prácticas de los individuos de la ciudad de Santiago, sobre todo para los más pobres. El barrio es lugar de trabajo, de 
las redes sociales, de la solidaridad, y también de la identificación o del estigma. Es un universo significante. Es territorio ocupado, apropiado y sentido por sus habitantes.

Si bien muchos de los pobres que habitan en la ciudad de Santiago han logrado formalizar su vivienda, se observa que las barreras para integrar el mercado laboral siguen estando presentes. Como se pudo constatar, los habitantes de El Castillo no trabajan solo en las comunas alejadas y que concentran el mercado laboral de la ciudad -zona oriente-, sino que muchos lo hacen en la misma comuna o comunas vecinas, en empleos realmente precarios. Esto constituye parte de las estrategias que ha debido desarrollar la población en relación con su empleo y los costos de movilidad asociados a ello.

Un caso que muestra la importancia de la proximidad es el de Luis ${ }^{2}$, de cincuenta y nueve ańos y portero de un centro terapéutico ubicado en El Castillo. Trabaja allí desde hace varios años y está consciente de las facilidades que le da este trabajo, sobre todo el poder desplazarse a su trabajo a pie o en bicicleta y no gastar en transporte. Como Luis hace turnos en el centro donde trabaja, puede gestionar mejor su tiempo y dedicarse a otros "trabajitos". Tiene un triciclo ${ }^{3}$, el que le permite transportar la mercancía para el negocio de dulces que maneja con su mujer en su casa. El día de la entrevista se había desplazado en su triciclo hasta la comuna vecina de Puente Alto para comprar la mercadería necesaria para vender en su negocio. Junto con este trabajo, vende plantas algunos días de la semana en una feria vecina y en la feria de la población, por lo que también debe desplazarse a los viveros que están en San Bernardo, trayectos que hace a pie o en el mismo triciclo. Dice que prefiere caminar o andar en su triciclo, pues esto le permite ahorrar el dinero que se gastaría en transporte público.

Otra confirmación de la importancia de la proximidad fue aportada por la situación de mujeres de bajos ingresos, para quienes la movilidad implica costos que les es difícil asumir. Por lo general deben ser capaces de articular empleo y labores domésticas, lo que viene a ser compensado en parte por la flexibilidad que otorga el empleo informal de proximidad. Si bien muchas de las mujeres pobres se ven confinadas al territorio próximo debido a la precariedad y a su condición de género, el trabajo que pueden conseguir en la proximidad se convierte en la posibilidad de cumplir con sus roles familiares y, al mismo tiempo, aportar monetariamente al hogar. El barrio se transforma así para muchas de ellas en un recurso que les permite sobrellevar de mejor manera su confinamiento territorial.

El caso de Lucía es un ejemplo de lo anterior. Debido a los problemas de locomoción que comenzaron a manifestarse luego de la restructuración del transporte de Santiago el año 2005, Lucía decidió economizar en tiempo y energías y dejó su antiguo trabajo (que estaba fuera de su comuna), a pesar de que el ingreso era mejor que el de las alternativas a su disposición en El Castillo. Lucía vende ahora ropa usada en la feria de su barrio. Este trabajo le acomoda más que el anterior debido a su flexibilidad y a la cercanía respecto de su hogar, lo que le permite ir y volver sin descuidar a su familia.

2 Respetando el anonimato de los entrevistados, todos los nombres que aparecen en este artículo fueron cambiados.

3 Triciclo: tipo de transporte, carro conducido por una bicicleta que permite trasportar objetos. Muy utilizado en las poblaciones pobres para transportar y vender cartones, comidas, etcétera. 
FIgURA 2-3| Habitantes del barrio El Castillo

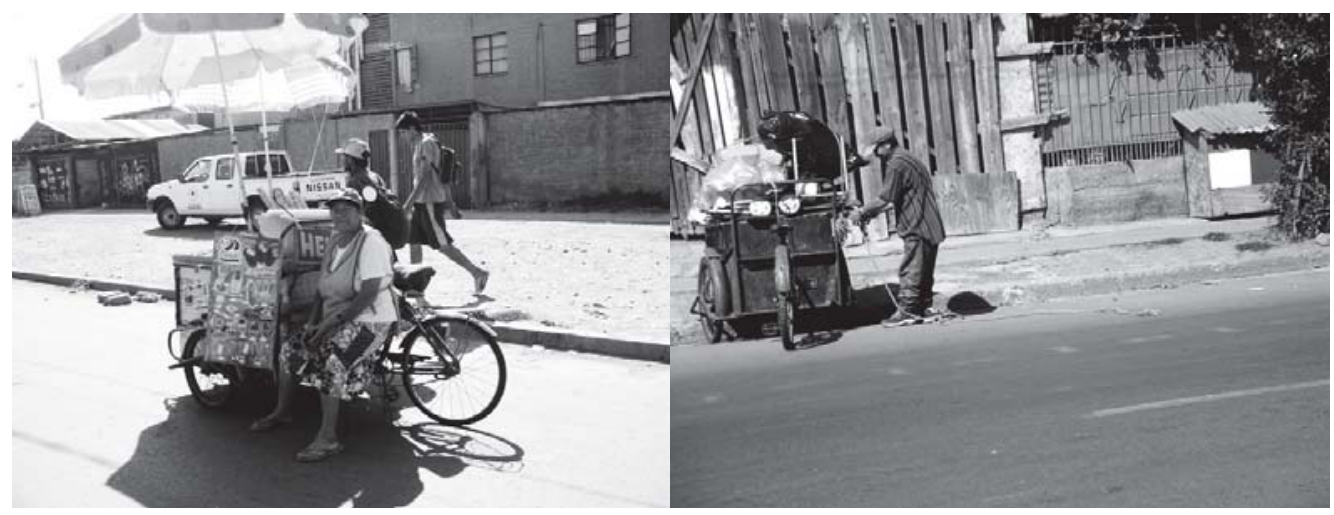

FUENTE FOTOS TOMADAS POR LOS AUTORES

Los relatos recogidos en El Castillo van mostrando que, en los barrios pobres, una movilidad cotidiana baja en el conjunto de la ciudad no solo se relaciona con la falta de ingresos o con un repliegue barrial; también corresponde a una estrategia que permite maximizar la capacidad de sus habitantes para movilizar recursos, los que muchas veces se encuentran más fácilmente en el entorno local. En este sentido, el territorio de proximidad y lo local se transforman en un espacio muy practicado, donde sus residentes son "muy móviles" y se sienten seguros.

Él [su papá] estuvo trabajando en el [paradero] 28 de Santa Rosa y no le gustó. Prefirió venirse, le salió un proyecto en la Municipalidad y se puso a trabajar como microempresario en la casa. Le sale mucho mejor.

Ahora [su mamá] se mantiene en la comuna, está trabajando aquí. Se pone a vender comida rápida, aquí compra todo (Hombre joven, El Castillo).

Es necesario reconocer, entonces, la contribución del sector informal local al desarrollo económico y al empleo, pues es la forma que tienen los hogares más pobres para sobrevivir mientras no surjan nuevas oportunidades. Esta "dependencia de la proximidad" deja al descubierto las lógicas, los recursos y las estrategias de sobrevivencia que los individuos ponen en marcha cotidianamente, al mismo tiempo que el barrio surge como un soporte frente a la dificultad que tienen sus habitantes de moverse más lejos.

En términos de movilidad residencial, se observó también cómo muchos jóvenes se han independizado de sus padres y han postulado a los subsidios que otorga la Municipalidad para obtener casa en la misma comuna. Si bien el entorno puede parecerles hostil, inseguro y con altos grados de delincuencia, los lazos que tienen con el territorio son muy valorados, pues cuentan para la cotidianidad de estos individuos.

ENTREVISTADOR: ¿Y por qué decidiste seguir viviendo en este sector?

entrevistado: Tengo una hija de siete años y en estos momentos yo elegí por conveniencia, porque mi hija es menor de edad, tiene siete años. En un minuto 
trabajaba mi pareja y necesitamos el apoyo directo de nuestra madre y abuela [que vive en el barrio] (Hombre adulto, El Castillo).

En los sectores populares la familia, los vecinos y los amigos desempeñan un papel importante en las prácticas de movilidad cotidiana. Sus desplazamientos, en una parte significativa, son para visitarlos, aunque en un radio bastante cercano, por lo que se privilegia el traslado a pie o en bicicleta. Ello viene a reforzar el arraigo con el lugar que se habita.

Tengo amigas aquí dentro de la villa y tengo una amiga en San Rafael y nos vamos a pie y nos venimos a pie. A la Muni [Municipalidad] vamos a pie. Vamos a pagar la luz y el agua a pie, no hay problema (Mujer adulta, El Castillo).

Sin embargo, no se puede caer en una visión ingenua y pensar que todos los individuos participan de un mismo anclaje y arraigo con el territorio. Si bien la proximidad como soporte y recurso permite un tipo de arraigo con el territorio, ello puede generar también una especie de "cautividad" en el lugar de residencia. Por ejemplo, frente al uso del territorio de proximidad como un recurso -sobre todo en lo que se refiere al trabajo-, nos encontramos con el caso de un hombre que rehúsa desplazarse y trabajar más allá de la escala de la proximidad. Este hombre evalúa cuidadosamente los costos (monetarios y físicos) que le significan viajar para trabajar demasiado lejos de su hogar, arriesgándose con ello a quedar excluido del mercado laboral. La proximidad se transforma en un confinamiento obligado en el territorio local.

Ya no puedo, no hay micros, ni una, porque no hay para arriba después (...) me cabrea, por eso no salgo, no salgo nunca. Si salimos, vamos por acá en la población; y si es que vamos, vamos al centro (Hombre adulto, El Castillo).

También la proximidad puede generar una suerte de "rechazo" al lugar, como en el caso de una pareja, Carmen e Ismael, para quienes la movilidad se construye ya no utilizando la proximidad, sino diferenciándose de ella. En este sentido, ya no es la proximidad sino la capacidad de movilidad cotidiana el elemento que permite superar la situación que les tocó vivir. Esta familia decidió hace muy poco comprar un automóvil, para ello pidieron un préstamo bancario. La decisión no fue fácil, ya que Ismael es el único que trabaja de la familia y su salario es bastante precario. A pesar de esto, el deseo de mejorar su calidad de vida fue más importante, lo que lo llevó a la decisión de endeudarse.

Si bien Carmen e Ismael son reconocidos en la población como personas muy activas y que han luchado para sacar adelante el barrio, y ella es una reconocida dirigente vecinal y presidenta del club deportivo, ambos desean cambiarse de casa en un futuro cercano, debido a los problemas de delincuencia y violencia que vive el barrio. La compra del auto ha sido así una estrategia de protección frente a la inseguridad del lugar, al mismo tiempo que se ha convertido en una forma de escape, de libertad y de accesibilidad hacia otras áreas de la ciudad, mientras esperan que el deseo de cambiarse de barrio se concretice. En este sentido, el habitar de esta familia se da como "atópico" (Lindón, 2005), ya que se valora la casa, pero se rechaza el 
entorno que la rodea. La movilidad del automóvil se transforma en la manera de sobrellevar la tensión de la proximidad (Lazo \& Calderón, 2011).

Se plantea, entonces, que entre el anclaje y el encierro, entre la inmovilidad local y la movilidad urbana, la relación de los individuos pobres con su territorio revela una gran ambivalencia y exige saber articular y utilizar los recursos de la proximidad y de la movilidad. Frente al aspecto "penalizante" de la proximidad, se da también que permite a los individuos sobrellevar la precariedad, el aislamiento y la falta de oportunidades, al insertarlos en un sistema de intercambios y solidaridades. Ello, sin embargo, puede constituirse en un obstáculo, porque encierra a los individuos y los obliga a replegarse en los márgenes de su barrio, además de que puede ser un factor que juegue en contra de una movilidad residencial.

\section{Comunidad Ecológica de Peñalolén}

El segundo terreno estudiado, la Comunidad Ecológica de Peñalolén, es un barrio formado en los años ochenta por un grupo de individuos de clase media-alta que se "autosegregó" en los márgenes de la ciudad, en busca de los ideales de comunidad y amor a la naturaleza.

Este barrio, emplazado en un área precordillerana de la ciudad y rodeado de naturaleza, tiene la particularidad de conservar un aire "rural", no estar totalmente urbanizado, tener caminos de tierra y algunas construcciones de adobe.

\section{Figura 4 | Vivienda Comunidad Ecológica de Peñalolén}

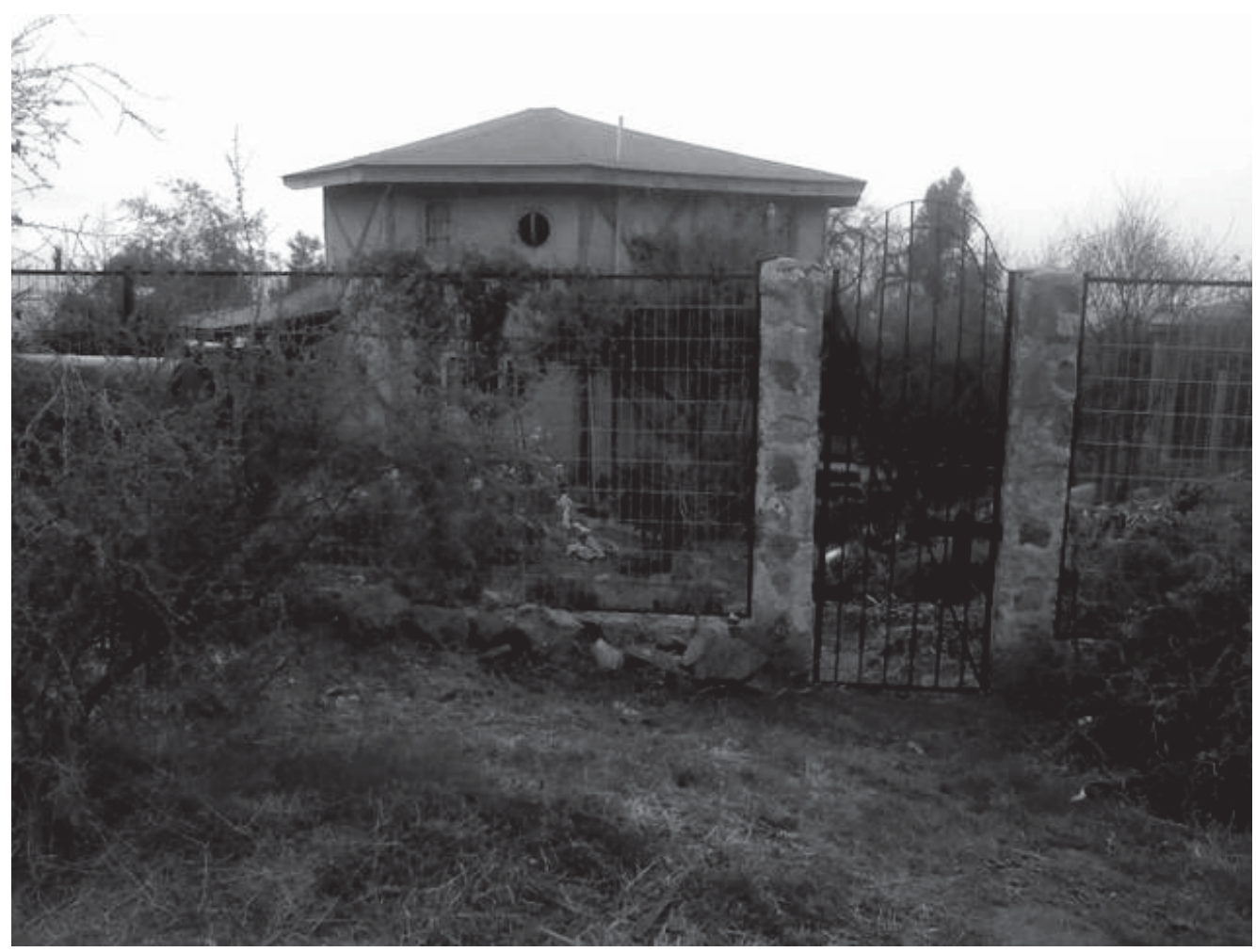

FUENTE FOTOS TOMADAS POR LOS AUTORES 
En este barrio las casas fueron levantadas por sus propios habitantes a partir de materiales nobles y construcciones acordes con la naturaleza. Esto hizo del espacio residencial y su entorno un territorio cargado de significaciones, que poco a poco fueron reforzando un anclaje particular en él.

Yo me acuerdo que nosotros pusimos los pilares de la tierra, y como ellos eran medios hippies [se refiere a sus padres] pusieron unos cristales e hicieron como un sahumerio (Mujer joven, Comunidad Ecológica).

La constitución de este barrio a partir del ideal de vida en comunidad llevó a que los vecinos, en los primeros años, cuando solo había unas pocas casas, se organizaran para abrir los caminos, ir a buscar agua, gestionar las labores internas, todo esto fue estableciendo lazos de solidaridad muy importantes.

Por otra parte, a diferencia del caso de El Castillo, donde la movilidad autónoma se configura en torno al barrio y se basa en medios de transporte como la caminata y la bicicleta, en la Comunidad Ecológica es la movilidad basada en el automóvil la que prima. El automóvil es sentido por los habitantes de la Comunidad como el medio que les permite gozar de mayor libertad, tener control del tiempo y del espacio y, por lo tanto, poder cumplir con sus múltiples obligaciones.

En este auto voy para todos los lados; es decir, el colegio, el supermercado, y de vez en cuando la medicina natural (...). Yo utilizo el auto, mis hijos las motos y mi esposo usa la camioneta (Mujer adulta, Comunidad Ecológica).

Sin embargo, esta movilidad necesita ser reforzada por medio de los recursos que da la proximidad. De hecho, y por tratarse de un barrio ubicado en una zona periférica y que no tiene muy buena accesibilidad, las redes de vecindad y de apoyo constituyen todavía un soporte para la cotidianidad de quienes viven allí. Ya no se trata de organizarse para traer el agua, como ocurría en los primeros años, sino de coordinar las salidas, compartir las tareas del cuidado de los hijos, apoyarse en los desplazamientos.

Tengo amigas. Por ejemplo, el otro día tenía que ir al doctor y era lunes, y tenía restricción. Y voy con una amiga, porque esa amiga tenía una hora y me llevó. Después yo la pasé a buscar. Como que trato, tengo una buena red de apoyo aquí. Hacemos acarreo, por ejemplo con los niños. Tengo una buena red de apoyo, tengo a los nińos en dos colegios distintos, entonces con los dos hago turnos. También voy con amigas al supermercado, de repente (...) los jueves lo voy a buscar [al hijo] y con mi hija tengo un trueque, porque yo también vendo alimento de perros y ahí alguien la va a buscar y a dejar, y yo se lo pago con una bolsa de alimento (Mujer adulta, Comunidad Ecológica).

La lejanía, la necesidad de automóvil y de una mayor disponibilidad de tiempo, hacen que muchas de las familias que viven en la Comunidad tengan que organizarse para realizar actividades en común, y con esto aliviar la tensión de la movilidad cotidiana.

Hay un tema de lejanía y la necesidad de tener automóvil que hace que muchos nos unamos. Hacer dedo en la Comunidad es una cosa que todos hacen; hasta yo he hecho dedo, todos pueden hacerlo (Hombre adulto, Comunidad Ecológica). 
Para uno que está en auto, está todo en cinco minutos. La mayoría de la gente tiene [auto], yo creo que es cien por ciento y es por una cosa de emergencia, de llevar a los niños a alguna parte, el mismo tema del colegio (...) siempre yo llevo y traigo gente (Mujer adulta, Comunidad Ecológica).

Otro factor que refuerza esta cercanía es el componente socioprofesional de los habitantes de la Comunidad. Muchos de ellos son profesionales liberales que no tienen la necesidad de integrarse al mercado de trabajo más formal y, por lo tanto, no requieren salir de la Comunidad Ecológica para encontrar trabajo.

Son artistas, artesanos, autodidactas, actores, microempresarios (...) debemos haber unas veinte personas que funcionamos acá en el barrio, gente que como máximo va a la Municipalidad (Hombre adulto, Comunidad Ecológica).

Por otro lado, moverse en las comunas espacialmente próximas, privilegiando la escala barrial y comunal, si bien se transforma en un soporte que permite seguir el ritmo de vida de la Comunidad, puede al mismo tiempo producir una especie de repliegue en la proximidad, sea en el domicilio o en el barrio, como ocurría, aunque con otros matices, en el caso de El Castillo.

Cada vez más abúlicos, ¡qué horrible!, todo más arriba. Además que los niños tienen como ene deporte, como que hacemos todo arriba (Mujer adulta, Comunidad Ecológica).

Como que he armado mi vida aquí. Tengo una feria a dos cuadras, el supermercado a diez minutos, como que vivo mi mundo aquí (Mujer adulta, Comunidad Ecológica).

Sin embargo, se debe mencionar que no todos los habitantes están igualmente arraigados al barrio. Sobre todo los residentes más nuevos y que han llegado recientemente a vivir a la Comunidad, no dudarían en dejar el barrio si esto fuese necesario por razones laborales, familiares o sociales. Ello da cuenta de las diferentes prácticas y relaciones que coexisten al interior de un mismo territorio.

Figura 5 Pancarta en defensa de la Comunidad Ecológica

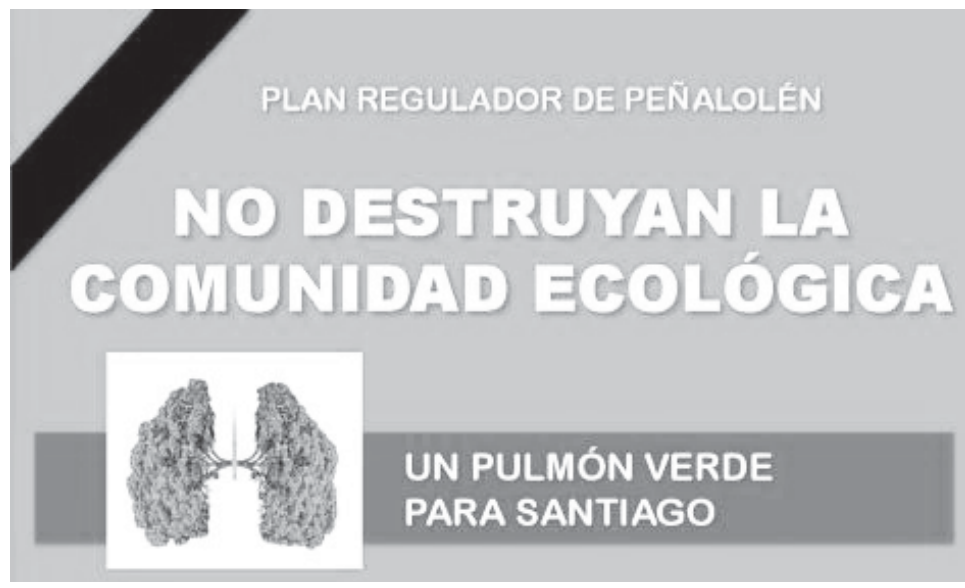

FUENTE HTTP://COMUNIDADECOLOGICAPENALOLEN.BLIGOO.COM/ 
De este modo, es posible plantear que la importancia que toma la Comunidad Ecológica, las redes creadas entre vecinos, el uso del automóvil privado, al igual que la posibilidad de trabajar in situ, actúan como elementos amortiguadores de las movilidades más extensas y cansadoras. En un contexto donde la instalación en la periferia de las clases medias solo puede realizarse teniendo como principal medio de transporte el automóvil privado, los relatos de estos habitantes dan cuenta de cómo el territorio de proximidad se constituye en un territorio "soporte" que tiene matices y que importa para las prácticas cotidianas de movilidad.

\section{Unidad Vecinal Portales (Villa Portales)}

El tercer y último terreno analizado fue la Unidad Vecinal Portales, proyecto emblemático de la construcción de la ciudad de Santiago en los ańos cincuenta. Este conjunto habitacional ubicado en el pericentro de la ciudad contaba con grandes espacios verdes, plazuelas y árboles. Las viviendas, casas y departamentos eran también espacios muy amplios, luminosos y bien equipados que favorecían la vida en su interior y la interacción entre las diferentes escalas.

Los habitantes de este barrio son familias de clase media, trabajadores afiliados a la Caja de Empleados Particulares -institución previsional disuelta en 1980-, a quienes se les dio la oportunidad de optar a una vivienda de calidad emplazada en el centro de la ciudad. Esta vivienda podía ser una casa o un departamento de dos pisos.

Mi esposo era empleado particular y nos vendieron este departamento y a mí me gustó porque era grande, tengo seis hijos, más mi esposo y yo, éramos ocho (Mujer mayor, Villa Portales).

En este sentido, la instalación y el querer quedarse en la villa permitió ir echando rápidamente raíces. Los más viejos hicieron su hogar y formaron su familia, se fueron estableciendo las redes sociales y vecinales, los más jóvenes fueron creando lazos de amistad, se casaron con gente de la villa, arrendaron o compraron una vivienda allí. Todo esto fue haciendo las relaciones más estrechas y el arraigo con el territorio, más sólido.

Los grandes espacios verdes con los que contaba la villa, sus jardines y árboles floridos, los grandes edificios y las amplias casas, fueron elementos que ayudaron a esta conexión entre el adentro y el afuera, a esta unión entre las escalas. La casa y el barrio eran uno solo.

De este modo, parece interesante dar cuenta de que en muchos de los relatos la casa nunca apareció como un ente aislado o separado; no se la concibe sin aquello que está más allá de ella, la villa. Así, una de las razones por las que se valora la casa es la villa misma. Este hecho diferencia a este territorio de lo que podría ocurrir en otros contextos más precarios, como El Castillo, donde algunos de sus habitantes solo habitan la casa y no el barrio. También la centralidad y la ubicación de que goza la villa acentúan hasta la actualidad la importancia de vivir en ella.

Este es como un lugar privilegiado, tiene locomoción para todos lados, tiene el Metro, si tú quieres ir en bicicleta puedes ir hasta el centro... (Mujer joven, Villa Portales). 
Figura 6 | La Unidad Vecinal Portales (Villa Portales) en la actualidad

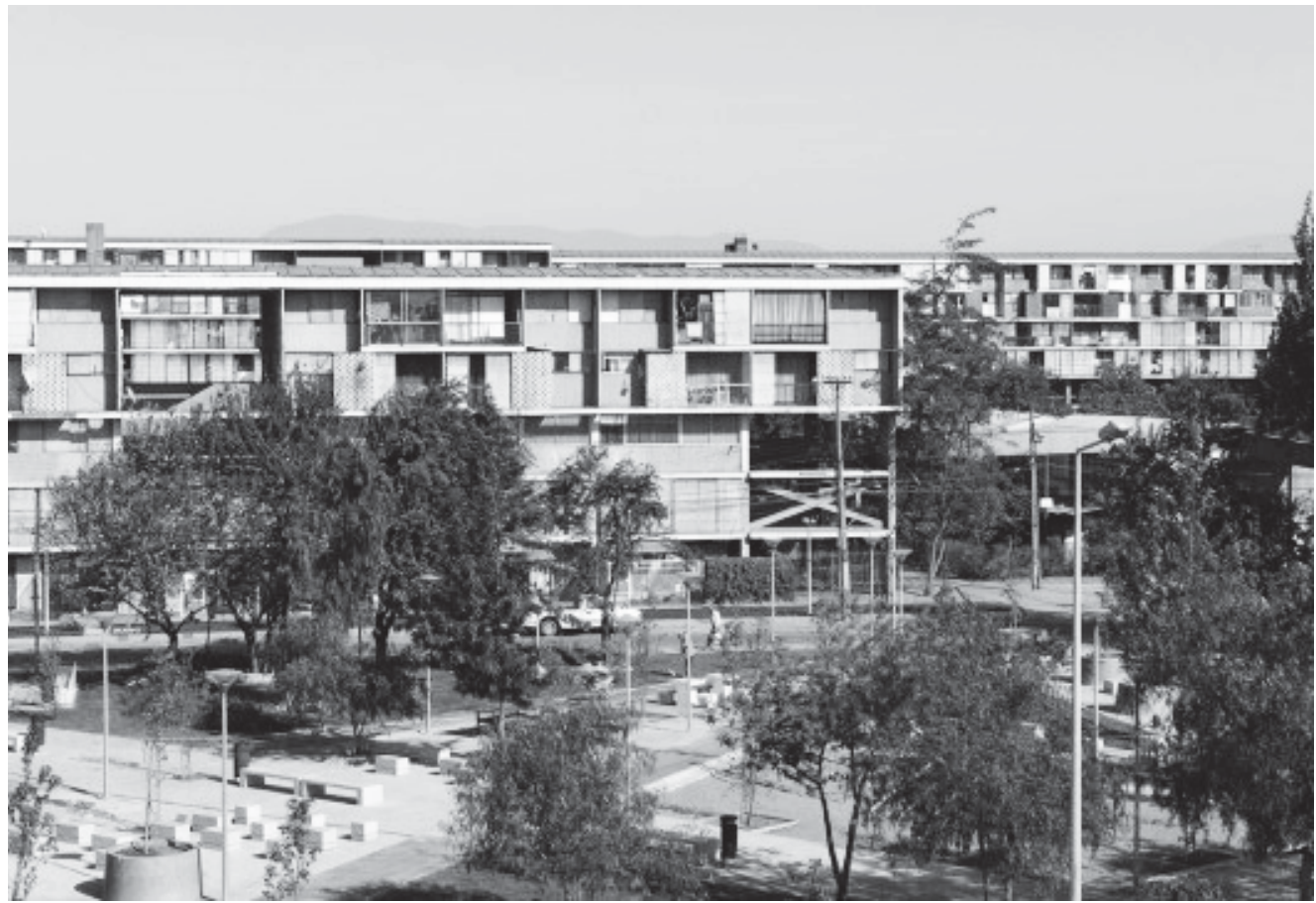

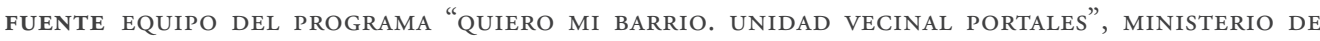
VIVIENDA Y URBANISMO, CHILE

Si se observa la villa y se escucha el relato de quienes la habitan se puede plantear que, para muchos individuos, los espacios del barrio se constituyen en lugares importantes, pues son territorios de circulación, de intercambio de servicios, de información, de conversaciones. La casa del vecino pasa a ser muchas veces un lugar familiar, un lugar al que se puede acudir en caso de necesidad, lugar de discusión y de encuentro.

Es especial esta villa está hecha para que todos nos topemos, nos saludemos (...) es que esto está hecho así, esto fue hecho para social, tener una vida social; por ejemplo, usted sale acá afuera y tiene la vereda altiro, de inmediato (Mujer adulta, Villa Portales).

En la proximidad se socializa y se consume. Los comercios son muy frecuentados para comprar pequeńas cosas, bebidas, dulces, pan, dando cuentas de micromovilidades a escala barrial. En estos comercios se conoce al dueño y este conoce a los habitantes de la villa. Incluso si no se tiene para pagar lo que se compra se lleva "fiado", es decir, se paga posteriormente, cuando esté disponible el dinero. La socialización, la familiaridad y la confianza son elementos que aún se practican entre quienes habitan Villa Portales.

Pero aquí me muevo con todas las cosas que me faltan. Conozco a la señora del negocio de la esquina, conversamos, allá en el departamento tengo a la otra vecina que de repente me puede pasar plata... (Mujer adulta, Villa Portales). 
Se constató que los relatos recogidos en Villa Portales sobrepasan la clásica oposición entre movilidad cotidiana e inmovilidad barrial. En este territorio, la tensión entre movilidad cotidiana e inmovilidad parece estar más equilibrada (Gustafson, 2001), pues a pesar de que muchos habitantes privilegien la escala de la proximidad, son capaces de moverse y desplazarse hacia otras escalas, cuestiones que son resueltas por la centralidad, la accesibilidad y los equipamientos con que cuenta la villa. Asimismo, el uso de capacidades y competencias individuales y familiares permite un mayor manejo de las diferentes escalas de la vida cotidiana.

Para serte honesta, una es porque le tengo amor. Me crié aquí en la villa y nos fuimos haciendo viejos todos. Unos se han casado, otros se han ido (...). La otra cosa es porque tengo todo cerca acá a mano y lo principal es porque no ha llegado la gente mala, entiendes tú, que te asalten en las esquinas (Mujer adulta, Villa Portales).

Sin embargo, existe otro perfil de habitantes que dista un poco de las características de los más arraigados y comprometidos con la villa. Se trata de un grupo de jóvenes que manifiesta un rechazo por el barrio, sobre todo por el proceso de deterioro en que se encuentra en la actualidad. En este caso, el territorio de proximidad funciona como un soporte de tipo más práctico que simbólico. Así ocurre con Fernando, de veinticinco años, que estudió en un conocido instituto de Santiago y trabaja en el centro de la ciudad, a muy pocos minutos de la villa. A pesar de que manifiesta un aprecio por el lugar, se implica poco y realiza muy pocas actividades en la proximidad. Dice no frecuentar el centro comercial que está a muy pocos pasos de la villa, no hacer trámites ni compras en la misma comuna, y menos salir a divertirse allí o las comunas vecinas. Ayudado por la buena accesibilidad de la villa, prefiere desplazarse en metro o en bus al centro comercial que está en el barrio alto de la ciudad o salir a divertirse más allá de su territorio de proximidad.

El mismo discurso de Fernando aparece en varios de los relatos de los jóvenes, y refleja a un grupo para el que la movilidad cotidiana es la que permite la diferenciación social. En este sentido, mientras no se tengan los recursos para mudarse a un barrio "mejor", la movilidad aparece como una forma de escapar de una proximidad no deseada y acceder a otros recursos.

Planteamos finalmente dos imágenes del barrio como soporte y su relación con la movilidad cotidiana en Villa Portales. La primera, aquella de un soporte más afectivo en la proximidad que se manifiesta por medio de una movilidad a pequeña escala (arraigada y sedentaria) o por medio de movilidades más intensas en la ciudad (arraigados pero móviles). La segunda, aquella representada por los individuos que ven en el barrio un soporte más práctico (o instrumental), donde el territorio de la villa le sirve al individuo, y permite una movilidad alta en la ciudad.

\section{Reflexiones finales}

A partir de esta aproximación a tres barrios de la ciudad de Santiago de Chile, retomamos la hipótesis planteada al inicio de este artículo al afirmar que el territorio de proximidad aparece como un soporte que ofrece los anclajes para la movilidad cotidiana de los individuos y sus familias. El territorio próximo sigue siendo, para 
los habitantes de Santiago, la escala intermedia a partir de la cual la vida en la ciudad toma sentido. Sin embargo, en un contexto de individualización creciente y donde la movilidad es un elemento muy importante, esta escala será movilizada y valorada de diversas maneras, dando lugar a una diversidad de prácticas y relaciones con el territorio.

Pudimos constatar que en Santiago no hay solo "individuos móviles" desprovistos de arraigo o, por el contrario, solo "habitantes de barrio con una movilidad reducida". Más bien, lo planteado en este artículo se acerca a aquello que Jean-Yves Authier (2002) llama las "diferentes maneras de habitar y de vivir la ciudad", es decir, las maneras que tienen los individuos de conjugar movilidad urbana, anclaje en la proximidad e inmovilidad. Esto último pudo ser observado en cada uno de los tres barrios estudiados; sin embargo, las combinaciones que tomaban la movilidad y la inmovilidad estaban supeditadas a la relación que se tenía con el territorio de residencia y a una multiplicidad de factores que rodeaban la experiencia urbana del individuo y su familia.

Asimismo, se pudo comprobar que la importancia del estudio de la movilidad remite no solo a las distancias recorridas, el uso de los medios de transporte o el acceso a determinados recursos; la movilidad también puede ser leída por la experiencia de la inmovilidad, el confinamiento o el arraigo que tienen los habitantes, es decir, las maneras cómo ellos componen, transforman y se apropian de los diferentes territorios que practican. Es por ello que resulta relevante y novedoso leer la movilidad a partir del grado de inscripción territorial del individuo y su relación con la proximidad.

Finalmente, este artículo quiere poner sobre la mesa la necesidad de indagar, en investigaciones futuras, en aquello que significa la movilidad y el territorio de proximidad para los habitantes, y el tipo de ciudad a la que aspiran. Ello al comprobar que muchos habitantes de la ciudad de Santiago todavía reivindican un derecho a la proximidad que se complementa con un derecho a la movilidad. De este modo, la movilidad aparece compuesta de dos caras donde se articulan, por un lado, la lentitud y la proximidad; y por el otro, la velocidad y la distancia.

\section{Referencias bibliográficas}

Adey, P. (2006). If mobility is everything then it is nothing: Towards a relational politics of (im) mobilities. Mobilities, 1(1), 75-94. doi: 10.1080/17450100500489080

Ascher, F. (1998). La fin des quartiers. En N. Haumont (Ed.), Lurbain dans tous ses états faire, vivre et dire la ville (pp. 183-201). París, Montreal: L'Harmattan.

Authier, J.-Y. (2002). Habiter son quartier et vivre en ville: les rapports résidentiels des habitants des centres anciens. Espaces et sociétés, 108(1), 89-110. En http://gallica.bnf. fr/ark:/12148/bpt6k56203928.image.f90.pagination

Authier, J.-Y., Bacqué, M.-H. \& Guérin-Pace, F. (2007). Le quartier : enjeux scientifiques, actions politiques et pratiques sociales. París: Éditions de la Découverte. 
Bonvalet, C. \& Dureau, F. (2000). Les modes d'habiter: des choix sous contraintes. En F. Dureau, V. Dupont, E. Lelièvre, J.-P. Lévy \& Th. Lulle (Coords.), Métropoles en mouvement : une comparaison internationale (pp. 131-153). París: Anthropos / Institut de Recherche pour le Développement (IRD). En http://horizon.documentation.ird.fr/ exl-doc/pleins_textes/divers07/010023867.pdf

Bourdin, A. (2005). Les mobilités et le programme de la sociologie. Cahiers Internationaux de Sociologie, 118(1), 5-5. http://dx.doi.org/10.3917/cis.118.0005

Certeau, M. de (2000). La invención de lo cotidiano. v. I. Artes de hacer. México D.F.: Universidad Iberoamericana, Departamento de Historia, Instituto Tecnológico y de Estudios Superiores de Occidente.

Cresswell, T. (2010). Towards a politics of mobility. Environment and Planning D: Society and Space, 28(1) 17-31. En http://www.africancitiesreader.org.za/reader/chapters/026_ TowardsaPoliticsofMobility.pdf

Di Méo, G. (1999). Géographies tranquilles du quotidien. Une analyse de la contribution des sciences sociales et de la géographie à l'étude des pratiques spatiales. Cahiers de géographie du Québec, 43(118), 75-93. doi 10.7202/022788ar

Duhau, E. \& Giglia, A. (2008). Las reglas del desorden: habitar la metrópoli. México, D.F.: Universidad Autónoma Metropolitana; Azcapotzalco: Siglo Veintiuno Editores.

Grafmeyer, Y. (2006). Le quartier des sociologues. En J.-Y. Authier, M.-H. Bacqué \& F. GuérinPace (Eds.), Le quartier : enjeux scientifiques, actions politiques et pratiques sociales (pp. 21-31) París: La Découverte.

Gustafson, P. (2001). Roots and routes: exploring the relation between place attachment and mobility. Enviromentand Behavior, 33(5), 667-686. doi:10.1177/00139160121973188

Hannam, K., Sheller, M \& Urry, J. (2006). Editorial: Mobilities, immobilities and moorings, Mobilities, 1(1), 1-22. doi: 10.1080/17450100500489189

Jirón, P. \& Iturra, L. (2011). Momentos móviles. Los lugares móviles y la nueva construcción del espacio público. Revista Arquitectura del Sur, 39, 44-57. En http://vivienda. uchilefau.cl/extension/pdfs/Jiron,Iturra_Momentos_Moviles.pdf

Joseph, I. (1998). La ville sans qualités. La Tour d'Aigues: Éditions de l'Aube.

Jouffe, Y. \& Campos, F. (2009). Movilidad para la emancipación o el arraigo. Ciudades, 25(82), 29-35.

Kaufmann, V. (2011). Un droit au changement et à la diversité. Métropolitiques. En http:// www.metropolitiques.eu/Un-droit-au-changement-et-a-la.html

Lannoy, P. \& Ramadier, T. (2007). La mobilité généralisée : formes et valeurs de la mobilité quotidienne. Lovaina-la-Nueva: Academia-Bruylant.

Lazo, A. (2012). Entre le territoire de proximité et la mobilité quotidienne. Les ancrages et le territoire de proximité comme support et ressource pour les pratiques de mobilité des habitants de la ville de Santiago du Chili. Tesis de Doctorado en Geografía y Planificación Territorial, Universidad de Toulouse in Le Mirail, Toulouse. En http://tel.archives-ouvertes.fr/tel00711072

Lazo, A. \& Calderón, R. (2011). La proximidad en las prácticas de movilidad cotidiana. El caso de un barrio de la periferia de Santiago de Chile. Revista Geográfica del Sur, 3.

Le Breton, E. (2004). Les épreuves de la dispersion (recherche exploratoire sur les expériences individuelles de la société dispersée. París: DRAST-PREDIT. En http://www.innovationstransports.fr/IMG/pdf/RMT04-002.pdf 
Lindón, A. (2005). El mito de la casa propia y las formas de habitar. Scripta Nova. Revista Electrónica de Geografía y Ciencias Sociales, 9(194). En http://www.ub.es/geocrit/sn/ sn-194-20.htm

Lindón, A. (2006). Del suburbio como paraíso a la espacialidad periférica del miedo. En A. Lindón, M.-A. Aguilar \& D. Hiernaux (Cords.), Lugares e imaginarios en la metrópolis (pp. 85-106). Barcelona: Anthropos / Universidad Autónoma de Madrid (UAM-I).

Martuccelli, D. (2006). Forgé par l'épreuve : l'individu dans la France contemporaine. París: Colin.

Márquez, F. (2006). El retorno del barrio. Mensaje, 55(555), 38-41. En http://biblioteca. uahurtado.cl/UJAH/msj/docs/2006/n555_38.pdf

May Du. (2009). Résistances tacites face à la requalification d'un quartier urbain en voie de gentrification. Regard à partir du quartier Le Maupas, Lausanne. [VertigO] La revue électronique en sciences de l'environnement, 9(2). doi:10.4000/vertigo.8782

Monnet ,J. (2010). Le territoire réticulaire. Revista Anthropos, 227, 91-104. En http://halshs. archives-ouvertes.fr/halshs-00533584

Ontiveros, T. (2006). Vivienda popular urbana y vida cotidiana. Ponencia presentada en el Congreso Nacional de Antropología, Mérida,Venezuela, 30/05 al 4/06/1998. En http://bit.ly/1lGLrKy

Pattaroni, L., Kaufmann, V., Pedrazzini, Y., Bolay, J-C., Rabinovich, A. (2008). People and territories: Urban Sociology meets the livelihood approach in the south. Documento de trabajo. NCCR North- South Dialogue, n² 20. En http://www.north-south.unibe.ch/ content.php/publication/id/2153

Pinson, D. \& Thomann, S. (2001). La maison en ses territoires : de la villa à la ville diffuse. París: L'Harmattan.

Rémy, J. (1996). Mobilités et ancrages: vers une autre définition de la ville. En M. Hirschhorn \& J.-M. Berthelot (Eds.), Mobilités et ancrages: vers un nouveau mode de spatialisation? (pp. 135-154). París: L’Harmattan.

Rodríguez, A. \& Winchester, L. (2004). Santiago de Chile: una ciudad fragmentada. En Santiago en la globalización: ¿una nueva ciudad? (pp. 115-136). Santiago de Chile: Ediciones SUR.

Salcedo, R. \& Pérez, F. (2006). La vida barrial como aproximación al barrio. En Reflexiones críticas del urbanismo posmoderno. Documento de trabajo. Pontificia Universidad Católica de Chile, Santiago de Chile.

Sheller, M. \& Urry, J. (2006). The new mobilities paradigm. Environment and Planning A, 38(2), 207-226. http://dx.doi.org/10.1068/a37268

Urry, J. (2003). Global Complexity. Cambridge, uk: Polity Press. 